${ }^{2} \mathrm{~A}$ and $\mathrm{E}$ doctor, London, United Kingdom

${ }^{3}$ Assistant Professor, Department of Medical Sciences, Dubai Pharmacy College, United Arab Emirates

${ }^{4}$ Medical Surgical Nursing, Shiraz University of Medical Science, Shiraz, Iran

${ }^{5}$ Department of Pathology, Shiraz University of Medical Science, Shiraz, Iran

\title{
A preservative with bleaching and emulsifying effects
}

\section{Corresponding author:}

Mehrab Dashtdar,

Department of Integrative Medicine,

Dubai Specialized Medical Center \&

Medical Research Lab, affiliated with

Dubai Medical College and Dubai Phar-

macy College, Dubai,

United Arab Emirates

e-mail:dr.mehrab@gmail.com
Medical Research Journal 2020;

Volume 5, Number 2, 86-91

10.5603/MRJ.a2020.0018

Copyright (C) 2020 Via Medica

ISSN 2451-2591

\begin{abstract}
In cosmetic products, additives are substances that aren't consumed as main ingredients, actually, they are added to these products in the processes of preparation, packaging or storage in order to make them safer, improve their appearance, help to present a stable, attractive and easier to apply the product, without being stricken by environmental conditions [1, 2]. The protection and quality of toiletries or medicine products are important elements in regards to the health of the consumers. Adding preservatives to the formulations helps the cosmetic manufacturer achieve the first objective of products i.e. meeting the requirements of the users while being safe under normal conditions of use. Despite advances in manufacturing conditions (raw materials with exhaustive bacteriological controls and manufacturing in sterile areas), and the containers used (single-dose ampoules, opaque and hermetic bottles which are used for precise amount), there is still the possibility of colonizing cosmetics without a preservative in their composition. Principally adding extra compounds as emulsifier and blanching agent causes more noxious compounds in the products, which should be avoided. Hence, it is desirable that some components of the formulation fulfill this function [3]. In our study, a combination of sodium thiosulfate and Citric acid contains emulsifiers and bleaching substances. When this mixture was added to Azadirachta indica (Neem) gum or Acacia Senegal (Gum Arabic), besides the above-mentioned properties, turned these gums into a thickener and stabilizer agent. This formulation can prevent the spreading of microorganisms. It will be shown from the findings and results that this formula can be used as a preservative agent in the cosmetic and pharmaceutical industry with significant emulsifying and bleach potential. The rare side effect of this additive is mild skin hypersensitivity reaction only in sensitive individuals.

Objective: The purpose of the study was to develop a powerful preservative based on synthetic and natural ingredients, with bleaching and emulsifying effects.

Key words: preservative; bleaching; emulsifying; sodium thiosulfate; citric acid; neem gum
\end{abstract}

Med Res J 2020; 5 (2): 86-91

\section{Introduction}

Additives are ingredients that are utilized in small quantities to administer particular characteristics to a cosmetic to create the merchandise more attractive regarding texture, scent, color as well as antioxidants, preservative, and surfactants contents.

\section{Preservative aspect}

The preservatives incorporated mainly into the products to avoid deterioration and prolong their commercial life to protect the user from the likelihood of infection against a pathogenic microorganism [4]. Obviously, if the merchandise neglects this aspect of the aesthetic component, this may lead to loss of revenue and commercial image of the manufacturing company. Nowadays chemical preservatives are the common method to control harmful microorganisms. Looking at chemical preservatives as poisonous substances, consumers' demand for fresh products with minimal harm is increasing. Moreover, there is the necessity of an antimicrobial agent of natural origin, thus, we aimed for a mixture of two or more components, interacting as additives or synergistic for controlling the microbial growth, at the same time, the final compound should 
be like a fresh product with fewer additives. It should be noted that the speed of microbiological deterioration not only depends on the microorganisms present, but also of the chemical combination of the merchandise and also the style of initial microbial charge [5]. Numerous plants, which contain natural antimicrobials, are discovered so far. For example, phenolic compounds from barks, stems, leaves, flowers, organic acids present in fruits, and phytoalexins produced in plants. Since this kind of anti-bacterial can be considered as relatively safe sources, not only can we have greater security, but better quality of food [6].

\section{Bleach aspect}

\section{Control of the browning reaction}

Enzymatic browning is an oxidation reaction in which molecular oxygen intervenes as a substrate catalyzed by a sort of enzyme. It is found in virtually all living things, from bacteria to humankind [7]. In humans, it is accountable for the formation of pigments of hair and skin. In the cephalopods, it produces the pigment of the ink and in the arthropods; it participates with the hardening of the cuticles of the carapace, by forming Quinones that react with the proteins and insolubilizing them. In vegetables, their physiological role is not known precisely. The enzyme that is blamed for browning is called polyphenoloxidase, phenolase, or tyrosinase, the latter is the case in animals since tyrosine is the main substrate in them. The term cresolase, applied to the plant enzyme, has also been used. It was first discovered in mushrooms, in which the browning effect after mechanical damage, like cutting, is incredibly evident. The natural control of the polyphenol oxidase activity is principally produced by the compartmentalization of the substrates [8]. The enzyme is found in plastids and chloroplasts (in higher plants), and within the cell cytoplasm, while phenolic compounds which will act on substrates accumulate in vesicles. When compartmentalization is broken by mechanical damage, like grinding, cutting, or freezing and thawing, the browning reaction may occur. The inhibition of the enzyme by the products of the reaction occurs as well. Additionally maintaining compartmentalization will cause the browning reaction to stop by acting on different factors:

- Avoiding Oxygen contact with the cutting surface

- Reducing the $\mathrm{pH}$

\section{- Denaturing the enzyme}

Generally, these factors act together. Thus, the decrease in $\mathrm{pH}$ can act initially by reducing the activity of the enzyme, (its optimum $\mathrm{pH}$ is between five and seven.), but also, if it's sufficiently low, denaturing it irreversibly. Reducers can act in several ways, including reversing the reaction of Quinones to phenols. They will also act directly on the active center of the enzyme, transforming copper 2 into copper 1, which dissociates more easily. Sulfite and cysteine additionally react with Quinones and reduce them to diphenols, hence inactivate the enzyme [9].

\section{Emulsifier aspect}

The term surfactant means Surface Active Agent. They are compounds capable of lowering the surface tension between two phases, for instance between a liquid and a solid or between two insoluble liquids. The emulsifiers form an enormous group of substances whose function is to stabilize the mixtures of two immiscible liquids. In the feeding context, the immiscible liquids are normally oil and water, and it will be understood that the effect of any type of emulsifier will vary according to the proportion of oil and water and that whether other ingredients such as starch, proteins are involved. Some of the compounds that function as emulsifiers in food also have complex properties on starch and proteins. Therefore, the term emulsifier is not the most appropriate, and perhaps the properties of these compounds had better describe the terms surfactants or "surfactants." All these surfactants act at a very low level (less than $2 \%$ of the weight of the product) and for this reason, they are classified as minor ingredients or food additives. There are few natural emulsifiers, and the only lecithin, obtained mainly from soybean seed, which has been commonly used. However, the use of specially prepared glycerol monoglycerides or related compounds has been known for about 40 years, and much more recently there has been a rapid development of other compounds, each with its particular surfactant and complexing characteristics in the food industry [10].

\section{Materials and methods}

The study was conducted in the Department of Microbiology, Dubai Pharmacy College for Girls, UAE, and Shiraz University of Medical Sciences, Iran, over a period of two years (2017-2019).

Sodium thiosulfate obtained from Changsha weichuang chemical co. Itd, China. Citric acid was obtained from the local market Dubai, UAE.

Preparation of emulsifier solution: for $100 \mathrm{~mL}$ of solution: dissolved 18 grams of a sample (in a ratio of $1: 2$ sodium thiosulfate - Citric acid) into $100 \mathrm{~mL}$ distilled water.

\section{Microorganisms in Fungi culture}

The following fungi were used: Aspergillus Niger, Aspergillus parasiticus, Candida albicans, which were 
provided by the Microbiology Laboratory of the Shiraz University of Medical Sciences.

\section{A. Sterile, selective fungi culture process}

Preparation of the strains

$100 \mu \mathrm{L}$ of a spore suspension was inoculated into Potato Dextrose Agar (PDA) plate and incubated at $28+2^{\circ} \mathrm{C}$ for 7 days.

\section{Agar well technique}

With a Drigalski spatula, $100 \mu \mathrm{L}$ of the spore suspension inoculated into PDA plates; with Punch holes, a five $\mathrm{mm}$ diameter made to which $10 \mu \mathrm{L}$ of solution added in different concentrations $(50,66,75,80$ and $100 \%)$. $10 \mu \mathrm{L}$ distilled water as a control. The plates incubated at $28+2^{\circ} \mathrm{C}$ for 8 days and the inhibition halos were measured every $24 \mathrm{~h}$., using traditional macroscopic and microscopic criteria to confirm their purity and species identity.

\section{B. Non-Sterile, non-selective Fungi Culture process}

We prepared non-Sterile condition, non-selective Fungi Culture Media as below:

1. 0.5-gram gelatin

2. 0.5-gram Tragacanth

3. 4-gram whole grain Psyllium seeds (powder)

4. 1 gram Tang drink mix (orange)

All the above ingredients mixed in $50 \mathrm{~mL}$ tap water in a container. In this substrate, the optimum temperature for the development of the fungi is between 25 and $30^{\circ} \mathrm{C}$.

\section{Statistical analysis}

The growth inhibition measurements analyzed against the Sodium thiosulfate - Citric acid (in a ratio of $1: 2)$ by analysis of variance ANOVA performed a single factor. In addition, a comparison of means was made with the Tukey test $(p<0.05)$, using the MINITAB statistical program (version 16).

\section{Results}

\section{A. in antibacterial activity aspect}

Tested samples: 1) 12 grams Citric acid in $100 \mathrm{~mL}$ water. 2) 18 grams of sample (Sodium thiosulfate - Citric acid in a ratio of 1:2) dissolved into $100 \mathrm{~mL}$ distilled water. 3) 6 grams sodium thiosulfate plus 12 grams of citric acid in $100 \mathrm{~mL}$ water. 4) 6 grams Sodium thiosulfate in $100 \mathrm{~mL}$ water. 5) Sample No. (2) After 18 months of room temperature storage.

\section{B. Antifungal activity aspect}

B1. In non-Sterile, non-selective Fungi Culture process After 4 days of incubation, Sodium thiosulfate - Citric acid combination significantly decreased the mycelial growth of Aspergillus Niger, Saccharomyces cerevisiae and Candida albicans $(p \leq 0.001)$ at increasing the concentration from 0.06 to $3 \mathrm{mg} / \mathrm{mL}$.

\section{B.2 in Sterile, selective Fungi Culture process}

In a ratio of $1: 2$, sodium thiosulfate - Citric acid showed an inhibitory effect on the growth of Candida albicans and Aspergillus Niger, presenting inhibition halos during the 8 days of incubation. Tukey's analysis $(p<0.05)$ indicated that after 8 days of incubation, there is a significant difference between the means of the $100 \%$ sample results and concentrations at 50 , 66 , and $75 \%$. On the other hand, all concentrations show relevant differences with respect to the control. The greatest effect at 8 days incubation presented by the sample at $100 \%$, with $28 \mathrm{~mm}$ inhibition halos for Aspergillus parasiticus, $220 \mathrm{~mm}$ for Aspergillus Niger, and $24 \mathrm{~mm}$ for Candida albicans (Tab. 3).

\section{C. in Emulsifier and bleaching aspect}

\section{Preparation of GA solutions}

For 5 grams of Gum Arabic powder, added to six $\mathrm{ml}$ of water and Formula, stirring with a mixer for 5 minutes then add three $\mathrm{ml}$ of Oil mixed for five minutes again, then centrifuged at a speed of 4000 RPM for 10 minutes.

Table 1. Zone of inhibition (in $\mathrm{mm}$ ) against the microbes by the different compounds

\begin{tabular}{lcccc}
\hline Samples & \multicolumn{4}{c}{ Zone of inhibition $(\mathbf{m m})$ Mean \pm S.D } \\
\hline & Escherichia coli & Staphylococcus aureus & Pseudomonas aeruginosa & Streptococcus pneumonia \\
\hline 1 & $20 \pm 0.577$ & $27 \pm 0.00$ & $30 \pm 0.00$ & Resistant \\
3 & $22 \pm 1.41$ & $25 \pm 0.00$ & $29 \pm 0.577$ & Resistant \\
4 & $21 \pm 0.577$ & $26 \pm 0.577$ & $25 \pm 0.577$ & Resistant \\
5 & Resistant & Resistant & Resistant & Resistant
\end{tabular}


Table 2. Inhabitation of Aspergillus Niger and Candida albicans growing by different concentrations of Sodium thiosulfate - Citric acid concentrations.

\begin{tabular}{|c|c|c|c|c|c|c|c|}
\hline \multirow{2}{*}{$\begin{array}{l}\text { Incubation } \\
\text { period }\end{array}$} & \multicolumn{7}{|c|}{ Sodium thiosulfate - Citric acid concentrations $\mathrm{mg} / \mathrm{mL}$ ( in a ratio of $1: 2$ ) } \\
\hline & $\begin{array}{c}0.00 \mathrm{mg} / \mathrm{mL} \\
\text { Control Group }\end{array}$ & $0.05 \mathrm{mg} / \mathrm{mL}$ & $0.06 \mathrm{mg} / \mathrm{mL}$ & $0.09 \mathrm{mg} / \mathrm{mL}$ & $1 \mathrm{mg} / \mathrm{mL}$ & $2 \mathrm{mg} / \mathrm{mL}$ & $3 \mathrm{mg} / \mathrm{mL}$ \\
\hline After 4 days & $\begin{array}{l}\text { Aspergillus } \\
\text { Niger Growing }\end{array}$ & $\begin{array}{l}\text { Aspergillus } \\
\text { Niger Growing }\end{array}$ & Not growing & Not growing & Not growing & Not growing & Not growing \\
\hline To 18 month & $\begin{array}{l}\text { Aspergillus } \\
\text { Niger Growing }\end{array}$ & $\begin{array}{l}\text { Aspergillus } \\
\text { Niger Growing }\end{array}$ & Not growing & Not growing & Not growing & Not growing & Not growing \\
\hline $\begin{array}{l}\text { After } 18 \\
\text { month }\end{array}$ & $\begin{array}{l}\text { Aspergillus } \\
\text { Niger Growing }\end{array}$ & $\begin{array}{l}\text { Aspergillus } \\
\text { Niger Growing }\end{array}$ & $\begin{array}{l}\text { Candida albicans } \\
\text { Growing, before } \\
\text { Aspergillus Niger }\end{array}$ & Not growing & Not growing & Not growing & Not growing \\
\hline
\end{tabular}

Table 3. Sterile and selective Fungi Culture process. Zone of inhibition in different 1:2 sodium thiosulfate - Citric acid Concentrations

\begin{tabular}{|c|c|c|c|c|c|}
\hline \multirow[t]{2}{*}{ Organisms } & \multicolumn{4}{|c|}{$\begin{array}{l}\text { 1:2 sodium thiosulfate - Citric acid Concentrations (\%) } \\
\qquad 100756650\end{array}$} & \multirow[t]{2}{*}{$\begin{array}{l}\text { distilled water as } \\
\text { a control }\end{array}$} \\
\hline & \multicolumn{4}{|c|}{ Zone of inhibition (mm) } & \\
\hline Aspergillus parasiticus & 28 & 20 & 14 & 8 & 0 \\
\hline Aspergillus Niger & 20 & 15 & 10 & 6 & 0 \\
\hline Candida albicans & 24 & 17 & 12 & 5 & 0 \\
\hline
\end{tabular}

A

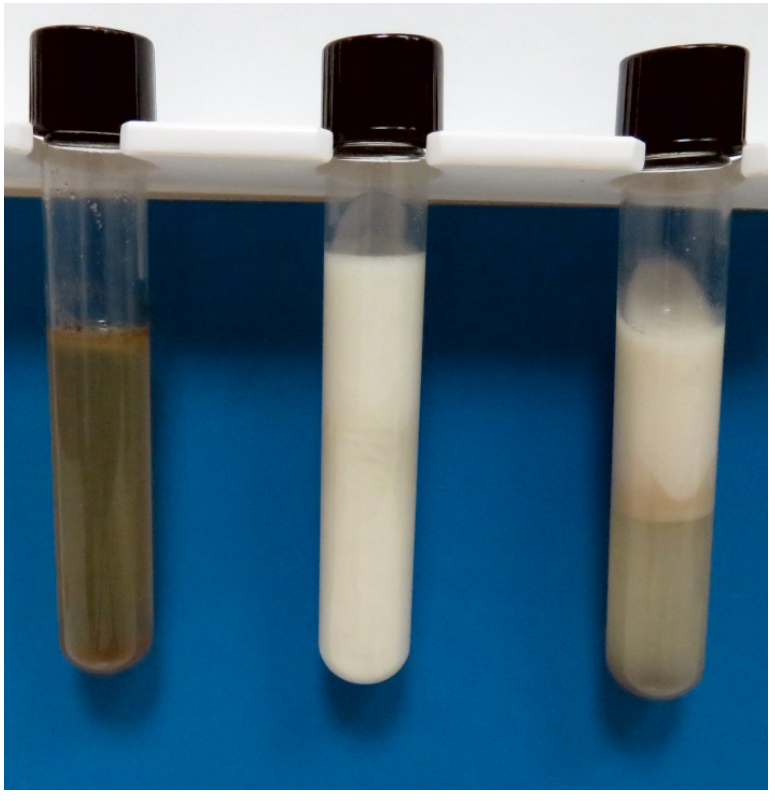

Figure 1. (A) Gum Arabic dissolved in water only; (B) Test tube contains the emulsifier after centrifugation at 4000 rpm for 10 minutes; (C) Test tube without Emulsifier, which breaks by centrifugation at $4000 \mathrm{rpm}$ for 10 minutes

\section{Discussion}

To research a specific fungal species, the presence of fungal microorganisms in the environment compels us to destroy other species, which have been able to contaminate the substance or related equipment [11, 12]. This may be achieved through sterilization, consisting of the destruction of all microorganisms. During this study, we carried out bacterial culture, both sterile and non-sterile fungal culture to observe fungicidal and fungi-static effects of our product together with bleaching and emulsifying effects. Our compound consists of Sodium thiosulfate and Citric acid dissolved in distilled water. Sodium thiosulfate is a neutral salt that dissociates easily in water to give sodium ions and thiosulfate. Sodium thiosulfate $\left(\mathrm{Na}_{2} \mathrm{~S}_{2} \mathrm{O}_{3}\right)$ a potent bleach neutralizer is used for the treatment of drinking water to destroy excess bromine and chlorine levels. In special cases can be used to remove oxygen in water purification residuals with chromium content [13]. It is also used in the industry of adhesives, arts, tanning, cleaning and maintenance, pulp, and paper. As a reducing agent, it is used in the polymerization of synthetic fibers. In developing pictorial film and prints, its common name is "Fixer" and is available in any photographic material provider but is likely to be more expensive than sodium sulfite [14]. As a medicine, it is used to manage cyanide poisoning and pityriasis versicolor. It has been used as a treatment for calciphylaxis in hemodialysis patients with end-stage renal disease [15]. In vivo, sodium thiosulfate is a cofactor of liver Rhodanese; the enzyme responsible for the detoxification of cyanide urinary thiocyanates eliminates its ability to convert cyanide into a nontoxic substance [16]. Sodium thiosulfate is not a toxic material and is used for medical purposes. However, when 
it decomposes, it produces noxious fumes of sulfur oxide, which can cause irritation to the eyes, skin, and mucous membranes, but when dissolves in substrate material (Neem gum) above-mentioned fumes are dispersed in the structure of the gel and decreases its provocative effects.

Citric acid is produced through the physical extraction of acid from lemon juice; currently, it is obtained mainly by Aspergillus Niger [17]. Citric acid has innumerable applications and uses preservative, flavoring, anti-oxidant, acidulant, and emulsifier [18]. Citric acid is a relatively common ingredient used in cosmetic products to balance $\mathrm{pH}$ levels. Small amounts of citric acid can be found in shampoos, hand and body soaps, facial cleansers, nail polish, and other cosmetic products.

Mixtures of preservatives are commonly used as complementary for the antibacterial and antifungal actions, but in this study, sodium thiosulfate-citric acid compound has both antibacterial and antifungal activities. In the emulsifier and bleaching aspects, the results showed that the Sodium thiosulfate - Citric acid solution significantly bleached \& emulsified the Media. Sodium thiosulfate solution reacts with Citric acid solution. The final reaction produced a form of white precipitate. In the exothermic reaction process of Citric Acid and Sodium thiosulfate, the following products composed:

$-2 \mathrm{C}_{6} \mathrm{H}_{8} \mathrm{O}_{7}+3 \mathrm{Na}_{2} \mathrm{~S}_{2} \mathrm{O}_{3}=3 \mathrm{H}_{2} \mathrm{~S}_{2} \mathrm{O}_{3}+2 \mathrm{Na}_{3} \mathrm{C}_{6} \mathrm{H}_{5} \mathrm{O}_{7}$

$-\mathrm{Na}_{2} \mathrm{~S}_{2} \mathrm{O}_{3}+2 \mathrm{H}_{2} \mathrm{O}=\mathrm{H}_{2} \mathrm{~S}_{2} \mathrm{O}_{3}+2 \mathrm{NaOH}$

$-2 \mathrm{NaOH}+\mathrm{H}_{2} \mathrm{SO}_{4}=\mathrm{Na}_{2} \mathrm{SO}_{4}+2 \mathrm{H}_{2} \mathrm{O}$

$-\mathrm{Na}_{2} \mathrm{~S}_{2} \mathrm{O}_{3}+\mathrm{H}_{2} \mathrm{SO}_{4}=\mathrm{H}_{2} \mathrm{SO}_{3}+\mathrm{Na}_{2} \mathrm{SO}_{4}+\mathrm{S}$

$-\mathrm{H}_{2} \mathrm{~S}_{2} \mathrm{O}_{3} \rightarrow \mathrm{H}_{2} \mathrm{O}+\mathrm{S}+\mathrm{SO}_{2}$

- $\mathrm{H}_{2} \mathrm{~S}_{2} \mathrm{O}_{3} \leftrightarrow \mathrm{H}_{2} \mathrm{SO}_{3}+\mathrm{S}$

- $2 \mathrm{H}_{2} \mathrm{~S}_{2} \mathrm{O}_{3} \leftrightarrow \mathrm{H}_{2} \mathrm{~S}+\mathrm{H}_{2} \mathrm{~S}_{3} \mathrm{O}_{6}$

- $2 \mathrm{H}_{2} \mathrm{~S}_{2} \mathrm{O}_{3} \leftrightarrow \mathrm{H}_{2} \mathrm{O}+\mathrm{H}_{2} \mathrm{~S}_{4} \mathrm{O}_{5}$

- $\mathrm{H}_{2} \mathrm{~S}_{3} \mathrm{O}_{6}=\mathrm{H}_{2} \mathrm{SO}_{4}+\mathrm{S}+\mathrm{SO}_{2}$

- $\mathrm{H}_{2} \mathrm{SO}_{3}+\mathrm{NaOH}=\mathrm{H}_{2} \mathrm{O}+\mathrm{Na}_{2} \mathrm{SO}_{3}$

- $\mathrm{Na}_{2} \mathrm{SO}_{3}+\mathrm{H}_{2} \mathrm{O} \rightarrow \mathrm{SO}_{2}+2 \mathrm{NaOH}$

- $\mathrm{SO}_{2}+2 \mathrm{NaOH}=\mathrm{Na}_{2} \mathrm{SO}_{3}+\mathrm{H}_{2} \mathrm{O}$

- $\mathrm{SO}_{2}+\mathrm{NaHCO}_{3} \rightarrow \mathrm{NaHSO}_{3}+\mathrm{CO}_{2}$

- $2 \mathrm{NaHSO}_{3} \rightarrow \mathrm{Na}_{2} \mathrm{~S}_{2} \mathrm{O}_{5}+\mathrm{H}_{2} \mathrm{O}$

End product contain: $\uparrow \mathrm{So}_{2}, \mathrm{~S} \downarrow, \mathrm{NaOH}, \mathrm{Na}_{2} \mathrm{SO}_{3}$, $\mathrm{Na}_{2} \mathrm{SO}_{4}$ and $\mathrm{Na}_{3} \mathrm{C}_{6} \mathrm{H}_{5} \mathrm{O}_{7}, \mathrm{Na}_{2} \mathrm{~S}_{2} \mathrm{O}_{5}$

Compounds that have bleaching effects include Sodium pyrosulfite $\left(\mathrm{Na}_{2} \mathrm{~S}_{2} \mathrm{O}_{5}\right)$, Sodium Sulfite $\left(\mathrm{Na}_{2} \mathrm{SO}_{3}\right)$, Sodium Sulfate $\left(\mathrm{Na}_{2} \mathrm{SO}_{4}\right)$, sulfur dioxide.

Compounds that have emulsifier effects include $\mathrm{NaOH}, \mathrm{Na}_{3} \mathrm{C}_{6} \mathrm{H}_{5} \mathrm{O}_{7}$, Sodium Sulfite $\left(\mathrm{Na}_{2} \mathrm{SO}_{3}\right)$, Sodium Sulfate $\mathrm{Na}_{2} \mathrm{SO}_{4}$ ).

Compounds that have preservative effects include $\mathrm{S}, \mathrm{SO}_{2}, \mathrm{Na}_{3} \mathrm{C}_{6} \mathrm{H}_{5} \mathrm{O}_{7}$, Sodium Sulfite $\left(\mathrm{Na}_{2} \mathrm{SO}_{3}\right)$, Sodium Sulfate $\left(\mathrm{Na}_{2} \mathrm{SO}_{4}\right)$, and Sodium pyrosulfite $\left(\mathrm{Na}_{2} \mathrm{~S}_{2} \mathrm{O}_{5}\right)$.

Sulfur dioxide acts as bleach removes oxygen from the cultured substance and makes it colorless. Sulfur dioxide is a gas, sold in a liquid form under pressure. It is a self-limiting additive in its use, in the sense that above a certain dose, it alters the taste characteristics of the product. It is especially effective in an acid medium, inhibiting bacteria and molds, and to a lesser degree, yeasts. It acts by destroying thiamine (vitamin B1), so it should not be used in those foods that contribute a significant proportion to the diet, as is the case of meat; however, it protects the vitamin $\mathrm{C}$ to some degree. During the cooking or industrial processing of food, sulfur dioxide and sulphites are lost partly by evaporation or by a combination with other components. The legal limits are always expressed in the content of sulfur dioxide. Sulfur dioxide and sulphites are widely used for the preservation of grape juices, musts, and wines, as well as for cider and vinegar [19, 20]. It is also used as a preservative in mustard sauces and especially in fruit, derivatives (juices, etc.) that will be used as raw material for other industries, which disappears, for the most part, during the subsequent processing. In addition to its action against microorganisms, sulfites act as antioxidants, particularly inhibiting the darkening reactions produced by certain enzymes in vegetables and crustaceans. For this purpose, it is authorized for use in canned vegetables and table olives, frozen cephalopods, and crustaceans. It is also used as an antioxidant in juices and beers. In some countries, it is used to preserve the fresh appearance of vegetables that are consumed in a salad. It can also be used to improve the appearance of the meat and give an impression of greater freshness, but this last practice is considered a fraud, by deceiving the buyer regarding the real quality. It is also harmful in the nutritional aspect by destroying thiamine (vitamin B1) contributed to a large proportion of meat.

Sodium citrate is chiefly used as a food additive, usually for emulsifiers, expansion agents, stabilizers, and preservatives. Sodium Citrate can be used as an emulsifier when making cheese [21]. It allows the cheese to melt without becoming greasy. Sodium citrate $\left(\mathrm{Na}_{3} \mathrm{C}_{6} \mathrm{H}_{5} \mathrm{O}_{7}\right)$ is a food additive (E331); it is used as a spice that would bring a bitter reminiscence of citrus fruits. It also works in milk products such as ice cream where it reduces the protein/calcium interactions of milk and gives a wetter ice-cream [22]. Sodium citrate reduces the impact of free calcium in solutions and better dissolves calcium-sensitive ingredients such as alginate or Gellan gum (Neem Gum \& Gum Arabic). In cosmetics and soap making, it can be used as a regulator of acidity and $\mathrm{pH}$, Sequestering, emulsifying, and stabilizing. Sodium citrate is an alkalizing agent that makes urine less acidic. When the urine is less acidic, it helps the kidneys to eliminate uric acid, thus preventing kidney stones and gout. Similarly, this medication can prevent and help treat some metabolic problems such as acidosis caused by kidney disease [23]. Sodium citrate is in the form of fine white powder. Sodium citrate is very effective in fighting acidity. It is thus used as a food 
additive in various preparations (Sweets, jellies, soft drinks...) to stabilize the acidity. On the packaging, it is referred to as E 331. It is also found in certain cosmetic products. The consumption of sodium citrate, while still limited, does not seem to represent a particular health hazard. The sodium citrate will bind to the free calcium ions, so they are not available to react with the sodium alginate.

\section{Conclusions}

The safety and quality of toiletries or medicine products are important elements in the health of the people. By adding preservatives to the formulations helps the cosmetics manufacturer achieve the primary objective of products that meet the needs of the consumer. These products are safe under normal conditions of use, although advances in manufacturing conditions (raw materials with exhaustive bacteriological controls and manufacturing in sterile areas.), as well as, the containers used (single-dose ampules, opaque and hermetic bottles for the precise amount); make it possible to prepare more and more cosmetics that do not include preservatives in their composition. Principally, adding extra compounds to act as emulsifiers and bleaching agents causes the more noxious compounds in the products. In these circumstances, it is possible that some of the components of the formulation fulfill this function. In our study, sodium thiosulfate-Citric acid combination contains emulsifier and bleaching substances, even when this combination added to Azadirachta indica (Neem) gum or Acacia Senegal (Gum Arabic.) in addition to the above-mentioned properties, it turned these gums into a thickener and stabilizer agent. This formulation can prevent the growth of microorganisms. It can be determined from the findings of the results that our formula can be used as a preservative agent in the cosmetic and pharmaceutical industry with significant emulsifying and bleach potential. The rare side effect of this additive is mild skin allergic reaction only in sensitive individuals.

\section{Conflicts of interest}

The authors declare that they have no conflicts of interest.

\section{Acknowledgments}

This research would not have been possible without the support of my family, professors, colleagues and friends. Special thanks to dean of Dubai Pharmacy college professor Saeed Ahmed Khan, for allowing me to conduct my research. Thanks to my family, for encouraging me in all of my pursuits and inspiring me to follow my dreams. Finally, I thank whoever reads this section and more of my thesis.

\section{References}

1. Food Additives \& Ingredients - Oveniew of Food Ingredients, Additives \& Colors. FDA Center for Food Safety and Applied Nutrition. Retrieved 11 April 2017.

2. Food Ingredients and Packaging Terms. FDA. January 4, 2018. Retrieved 9 September 2018.

3. Japanese Standards Association: ISO/JIS Standards on Sterilization of Health Care Products. 2011.

4. LückE, Lipinski GWV. Foods, 3. Food Additives. Ullmann's Encyclopedia of Industrial Chemistry. 2000, doi: 10.1002/14356007.a11_561.

5. Siquet F. Antibacterial agents and preservatives. In: Paye M, Barel $A O$, Maibach HI. ed. Handbook of Cosmetic Science and Technology. Taylor \& Francis Group, Boca Raton 2009: 223-231.

6. Dashtdar M, Dashtdar M, Dashtdar B, et al. In-Vitro, Anti-Bacterial Activities of Aqueous Extracts of Acacia catechu (L.F.)Willd, Castanea sativa, Ephedra sinica stapf and shilajita mumiyo Against Gram Positive and Gram Negative Bacteria. Journal of Pharmacopuncture. 2013; 16(2): 15-22, doi: 10.3831/kpi.2013.16.014

7. Finot PA, Aeschbacher HU, liurrell RF, Liardon R. The Maillard Reaction in Food Processing, Human Nutrition and Physiology. Advances in Life Sciences. Birkhäuser Basel, Birkhauser 1990.

8. Mazzei R, Drioli E, Giorno L. Biocatalytic membranes and membrane bioreactors. In: Drioli E, Giorno L. ed. Comprehensive membrane science and engineering, vol 3. Elsevier B.V., Oxford 2010: 195-212.

9. Macheix JJ, Sapis JC, Fleuriet A. Phenolic compounds and polyphenoloxidase in relation to browning in grapes and wines. Crit Rev Food Sci Nutr. 1991; 30(4): 441-486, doi: 10.1080/10408399109527552, indexed in Pubmed: 1910524.

10. Garti, Nissim and Reichman, Dov. „Hydrocolloids as Food Emulsifiers and Stabilizers," Food Structure: Vol. 12: No. 4, Article 3. 1993.

11. Peleg AY, Hogan DA, Mylonakis E. Medically important bacterial-fungal interactions. Nat Rev Microbiol. 2010; 8(5): 340-349, doi: 10.1038/nrmicro2313, indexed in Pubmed: 20348933.

12. Gots R, Layton N, Pirages S. Indoor Health: Background Levels of Fungi. AlHA Journal. 2003; 64(4): 427-438, doi: 10.1080/15428110308984836.

13. Barberá J, Metzger A, Wolf M. Sulfites, Thiosulfates, and Dithionites. UIImann's Encyclopedia of Industrial Chemistry. 2012, doi: 10.1002/14356007. a25 477

14. Sowerby ALM. Dictionary of Photography: A Reference Book for Amateur and Professional Photographers. Iliffe Books Ltd., London 1961: 324-326.

15. Zitt E, König M, Vychytil $A$, et al. Use of sodium thiosulphate in a multi-interentional setting for the treatment of calciphylaxis in dialysis patients. Nephrol Dial Transplant. 2013; 28(5): 1232-1240, doi: 10.1093/ndt/gfs548, indexed in Pubmed: 23291368

16. Schulz V, Gross R, Pasch T, et al. Cyanide toxicity of sodium nitroprusside in therapeutic use with and without sodium thiosulphate. Klin Wochenschr. 1982; 60(22): 1393-1400, doi: 10.1007/BF01716244, indexed in Pubmed: 7176461.

17. Gupta S, Sharma C. Citric acid fermentation by the mutant strain of theAspergillus niger resistant to manganese ions inhibition. Biotechnol Lett. 1995; 17(3): 269-274, doi: 10.1007/bf01190635.

18. Verhoff F. Citric Acid. Ullmann's Encyclopedia of Industrial Chemistry. 2000, doi: 10.1002/14356007.a07 103.

19. Jackson RS. Wine science: principles and applications. Elsevier/Academic Press, Amsterdam, Boston 2008.

20. Guerrero R, Cantos-Villar E. Demonstrating the efficiency of sulphur dioxide replacements in wine: A parameter review. Trends in Food Science \& Technology. 2015; 42(1): 27-43, doi: 10.1016/j.tifs.2014.11.004.

21. Zittle CA, Monica ESD, Custer JH. Effect of Certain Salts on Precipitation of Casein by Calcium Chloride and Heat. Journal of Dairy Science. 1957; 40(3): 280-288, doi: 10.3168/jds.s0022-0302(57)94475-2.

22. Zittle CA, DellaMonica ES, Rudd RK, et al. Binding of calcium to casein: Influence of $\mathrm{pH}$ and calcium and phosphate concentrations. Arch Biochem Biophys. 1958; 76(2): 342-353, doi: 10.1016/0003-9861(58)90159-0.

23. Phisitkul S, Khanna A, Simoni J, et al. Amelioration of metabolic acidosis in patients with low GFR reduced kidney endothelin production and kidney injury, and better preserved GFR. Kidney Int. 2010; 77(7): 617-623, doi: 10.1038/ki.2009.519, indexed in Pubmed: 20072112 